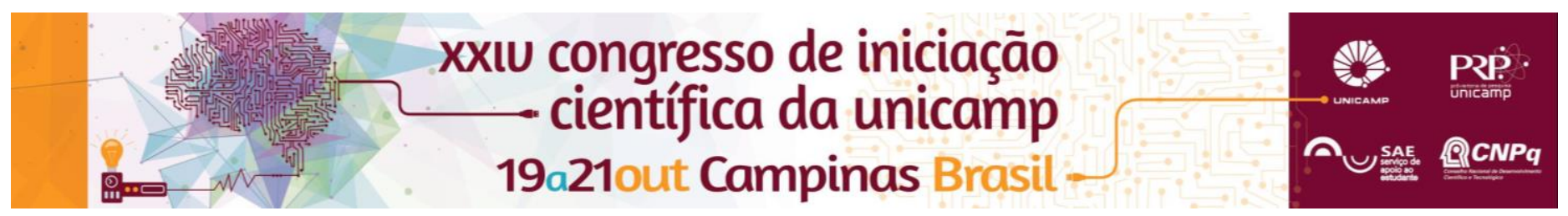

\title{
AVALIAÇÃO DE PROCESSOS DE SEPARAÇÃO COM MEMBRANAS (ULTRAFILTRAÇÃO E NANOFILTRAÇÃO) NA CONCENTRAÇÃO DE COMPOSTOS BIOATIVOS DA FOLHA DE GRAVIOLA (Annona muricata L.)
}

\author{
Cinthia S. Navarro*, Gustavo L. da Silva, Ingrid V. M. de Moraes, Flávio L. Schimidt.
}

\begin{abstract}
Resumo
Extratos hidroalcoólicos contendo $50 \%$ e $70 \%$ de etanol obtidos a partir de folha de graviola foram submetidos aos processos de UF e NF a fim de obter frações ricas em compostos fenólicos. As frações obtidas dos processos (alimentação, permeado e retido) foram analisadas quanto à sua capacidade antioxidante (ORAC e ABTS) e ao seu conteúdo de fenólicos totais, a fim de avaliar a seletividade das membranas a esses compostos. De acordo com os resultados obtidos conclui-se que as membranas avaliadas mostraram-se bastante efetivas na separação e concentração dos compostos de interesse da folha de graviola, que geralmente são descartadas durante a poda das árvores nos cultivos comerciais, mostrando-se como tecnologias viáveis e aplicáveis na retenção desses compostos.
\end{abstract}

\section{Palavras-chave:}

Compostos fenólicos, ultrafiltração, nanofiltração.

\section{Introdução}

Muitos compostos bioativos têm sido encontrados na gravioleira, dentre eles os compostos fenólicos, principais responsáveis por sua forte atividade antioxidante, sendo encontrados principalmente em sua folha, casca, tronco e sementes ${ }^{1}$. Extratos vegetais e infusões de diversos tipos de plantas têm sido amplamente comercializados com diferentes apelos farmacológicos. Contudo, na maioria das vezes, suas concentrações não são determinadas e especificadas, ou ainda, não estão em concentrações adequadas para obtenção do efeito desejado. Sendo assim, esse trabalho visa testar o uso de tecnologia de membranas na separação e concentração dos compostos de interesse da folha de graviola utilizando os processos de UF e NF, a partir de extratos hidroalcoólicos ricos em compostos fenólicos totais e alta capacidade antioxidante.

\section{Resultados e Discussão}

Para todas as membranas estudadas, as diferenças entre alimentação, permeado e retido foram significativas $(p<0,001)$. Os processos UF e NF utilizando extrato com $50 \%$ de $\mathrm{EtOH}$ apresentaram maior retenção dos compostos fenólicos e também maior capacidade antioxidante, medida por ABTS e método ORAC (Tabela 1). Isso está de acordo com estudos anteriores que destacam uma menor solvatação pelo EtOH em comparação com a água, provocando um alargamento do diâmetro nominal dos poros e, consequentemente, menor retenção dos compostos. ${ }^{2}$

Tabela 1. Coeficiente de retenção de compostos bioativos nos processos de UF e NF utilizando extratos de graviola $50 \%$ e $70 \%$ de $\mathrm{EtOH}$ em água (v/v).

\begin{tabular}{cccc}
\hline Processo & $\begin{array}{c}\text { Fenólicos } \\
\text { Totais (\%) }\end{array}$ & ABTS (\%) & ORAC (\%) \\
\hline NF270 50\% & $97.88 \pm 0.08^{\mathrm{A}}$ & $97.15 \pm 0.31^{\mathrm{A}}$ & $96.47 \pm 0.06^{\mathrm{A}}$ \\
NF270 70\% & $94.23 \pm 3.20^{\mathrm{AB}}$ & $95.81 \pm 0.75^{\mathrm{A}}$ & $91.77 \pm 0.83^{\mathrm{B}}$ \\
UH004 50\% & $87.29 \pm 0.44^{\mathrm{B}}$ & $86.81 \pm 0.64^{\mathrm{B}}$ & $77.45 \pm 2.05^{\mathrm{C}}$ \\
UH004 70\% & $75.11 \pm 0,68^{\mathrm{C}}$ & $86.77 \pm 1,04^{\mathrm{B}}$ & $77.20 \pm 0.57^{\mathrm{C}}$ \\
\hline
\end{tabular}

A NF mostrou coeficientes de retenção mais elevados em comparação com a UF, conforme esperado. No entanto, os elevados coeficientes de retenção observados nos processos UF foram surpreendentes (acima de 75\%), pois os compostos de interesse neste estudo têm uma massa molecular entre 100 e $700 \mathrm{~g} / \mathrm{mol}$, sendo muito menor do que o peso molecular de corte da membrana utilizada (4000 g/mol). Este resultado pode ser explicado pelo fato de os compostos fenólicos, os quais são responsáveis pela capacidade antioxidante, poderem estar fortemente ligados a macromoléculas encontradas na matriz vegetal, especialmente complexados com hidrocarbonetos, prejudicando assim sua passagem através dos poros.

Com relação a análise do fluxo de permeado, o tempo médio para o processo de NF direto atingir um fator de concentração volumétrico (FCV) de 1,7 era $37,5 \%$ inferior para o extrato $50 \%$ de $\mathrm{EtOH}$ em relação ao extrato $70 \%$ EtOH. Essa diferença de tempo foi menor para o processo UF $(19,9 \%)$. O fluxo mais elevado para processos com extrato hidroalcoólico $50 \%$ pode ser explicado pela natureza hidrofílica da membrana utilizada, onde fluxos mais elevados foram obtidos com solventes mais polares.

\section{Conclusões}

Pode-se concluir que a utilização do processo de separação com membrana de ultrafiltração de 4kDa se mostra um processo eficiente na retenção dos compostos bioativos de extrato hidroalcoólico de graviola, no que se refere a tempo e concentração de composto retido.

\section{Agradecimentos}

Ao CNPq, pelo apoio financeiro da bolsa. À Profa Míriam Dupas Hubinger, do Departamento de Engenharia de Alimentos, FEA/UNICAMP, pelo empréstimo do equipamento de membranas utilizado nesta pesquisa e ao Laboratório de Análises do Departamento de Ciência de Alimentos, em nome da Profa Helena Godoy e da técnica Marcela, pelo uso da microleitora utilizada nas análises de ORAC.

${ }^{1}$ ALALI, F.Q.; LIU, X.X.; McLAUGHLIN, J. L. Annonaceous acetogenins: recent progress. J. Nat. Products, v. 62, n. 3, p. 504-540, 1999.

${ }^{2}$ Rabelo, R. S., Machado, M. T.C., Martínez, J., Hubinger, M., D., 2016. Ultrasound assisted extraction and nanofiltration of phenoliccompounds from artichoke solid wastes. J. Food Eng. 178, 170-180. 